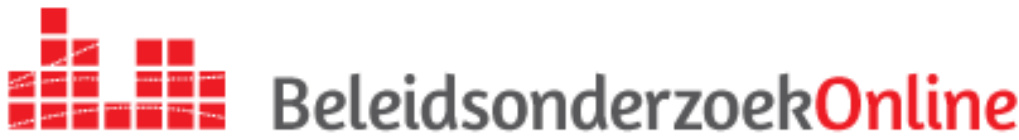

Citeerwijze van dit artikel:

Ronald Hoekstra, 'Wat is de meerwaarde van onze rekenkamer? Introductie van een model

om de doorwerking van rekenkameronderzoek te meten', bso 2013, oktober-december,

DOI: 10.5553/Beleidsonderzoek.000025

DOI: 10.5553/Beleidsonderzoek.000025

\section{Wat is de meerwaarde van onze rekenkamer? Introductie van een model om de doorwerking van rekenkameronderzoek te meten}

Ronald Hoekstra

\section{Inleiding: lokale rekenkamers op zoek naar hun meerwaarde}

\section{Wettelijke verplichting}

Met de 'dualisering' is er de verplichting voor gemeenten en provincies om een rekenkamer of rekenkamerfunctie in te stellen. De wettelijke verplichting voor gemeenten geldt sinds 1 januari 2006, die voor provincies sinds 1 januari 2005. De Gemeentewet respectievelijk de Provinciewet geeft nadere bepalingen over de inrichting en werkwijze. De wettelijke taak van de lokale rekenkamer is dat zij de doelmatigheid, de doeltreffendheid en de rechtmatigheid onderzoekt van het door het gemeentebestuur of provinciebestuur gevoerde bestuur. In de praktijk zien we dat inmiddels ruim tweehonderd rekenkamercommissies en rekenkamers actief zijn. Voor de leesbaarheid duiden we ze samen aan met 'lokale rekenkamers'. Meestal gaat het om kleine lokale bureaus met een beperkt budget van enkele tienduizenden euro's. Soms ook om grotere bureaus met een eigen staf en een budget van enkele honderdduizenden euro's (bijvoorbeeld Rekenkamer Amsterdam, Rekenkamer Rotterdam of de Randstedelijke Rekenkamer voor de provincies Noord-Holland, Zuid-Holland, Utrecht en Flevoland). Hoewel een budget van enkele honderdduizenden euro's veel geld is, is het relatieve budget voor rekenkameronderzoek ten opzichte van de jaarbudgetten van lokale overheden zeer gering te noemen.

\section{Meerwaarde?}

In de eerste pioniersjaren (vanaf 2005/2006) ging veel aandacht uit naar het opzetten van de eerste lokale rekenkamers en het uitdenken van passende werkprocedures, methoden en technieken. Daarbij werd het werk van de Algemene Rekenkamer als inspirerend voorbeeld genomen. Hoewel de ontwikkeling van het lokale rekenkameronderzoek nog steeds gaande is, zijn de pioniersjaren nu wel voorbij. De interne discussie in rekenkamerland verschuift mee van aandacht voor organisatiestructuur naar aandacht voor het feitelijk functioneren van de lokale rekenkamers. Verschillende rekenkamers hebben 
zichzelf intussen geëvalueerd of in opdracht van de gemeente of provincie laten evalueren. Een bijzonder relevante onderzoeksvraag is in deze gevallen wat de meerwaarde nu eigenlijk is geweest van het werk van de lokale rekenkamer. Neemt de kwaliteit van het lokale bestuur toe vanwege het werk van de lokale rekenkamers? Om die vraag te beantwoorden zien we dat in de evaluaties aandacht besteed wordt aan het vraagstuk van de doorwerking van rekenkameronderzoek. In bijvoorbeeld de Evaluatie van de provinciale en gemeentelijke rekenkamers (2011), in opdracht van het ministerie van BZK, gaat een van de deelvragen over de vraag wat de impact van het rekenkameronderzoek is geweest (deelvraag 1f). Opvallend is dat de onderzoekers (Berenschot) achter deze deelvraag tussen leeshaken hebben toegevoegd: (worden de aanbevelingen opgevolgd?). Blijkbaar hebben ze de 'impact' willen meten door na te gaan of de aanbevelingen van de rekenkamer wel of niet zijn opgevolgd. Dat is op zich een goede indicator, en vooral een goed onderzoekbare indicator. Maar als enige indicator heeft het zo zijn beperkingen. Er zijn immers meer manieren waarop onderzoek impact kan hebben dan via het opvolgen van de aanbevelingen alleen. De literatuur over doorwerking biedt daarover de nodige inzichten. In dit artikel staan we kort stil bij die theoretische achtergrond, geven een definitie en beschrijven zes factoren die van invloed zijn op de doorwerking van een rekenkameronderzoek.

\section{Theorie van doorwerking}

\section{Literatuur}

Vanwege het praktische karakter van dit artikel staan we slechts kort stil bij de theoretische (wetenschappelijke) achtergrond van doorwerking. Deze paragraaf wil een introductie bieden en de geïnteresseerde lezer op weg helpen.

Doorwerking is een term die verwijst naar het gebruik van (wetenschappelijke) kennis in beleidsprocessen. We hebben ervoor gekozen om vooral te citeren uit de publicatie Doorwerking van strategische beleidsadvisering van Bekkers et al. uit 2004. ${ }^{1}$ BBekkers et al. doen daarin verslag van hun onderzoek naar de doorwerking van adviesraden bij de rijksoverheid. De positie van deze adviesraden lijkt vanwege hun onafhankelijkheid en directe relatie met de overheid op die van de lokale rekenkamers. Inzichten uit deze publicatie zijn volgens ons ook relevant voor lokale rekenkamers.

Bekkers et al. geven aan dat: 'een van de inzichten uit de literatuur over kennisgebruik is dat het moeilijk is om doorwerking:

1. te conceptualiseren, dat wil zeggen wat het inhoudelijk betekent en vast te stellen welke vormen bij welke doelgroepen van doorwerking zijn te onderkennen; en

2. te operationaliseren, dat wil zeggen daadwerkelijk meetbare grootheden te ontwerpen die recht doen aan de verscheidenheid van typen en vormen van doorwerking, en aan meer geavanceerde doorwerkingspatronen (verwijzende naar Sabatier \& Jenkins-Smith, 1988).' (Bekkers et al., 2004: 5)

Deze moeilijkheden zien we ook terug in de discussie binnen rekenkamerland over doorwerking. Het is niet altijd duidelijk wat doorwerking betekent voor de verschillende gebruikers van rekenkameronderzoek (gemeenteraad, B\&W, provinciale staten, gedeputeerde staten, ambtenaren, onderzochte instellingen) en hoe dat te meten is. Zoals we al in de inleiding opmerkten, wordt 
doorwerking voor het gemak meetbaar gemaakt door na te gaan of aanbevelingen overgenomen zijn of niet. Hiermee wordt geen recht gedaan aan het meervoudige karakter van doorwerking.

\section{Vormen van doorwerking}

Er kunnen verschillende vormen van doorwerking worden onderscheiden. De vier vormen van doorwerking die Bekkers et al. beschrijven en die in onderstaande tabel staan, komen we in de literatuur vaak tegen.

\section{Vorm van Omschrijving
doorwerking}

Instrumentele

Het advies leidt tot een directe verandering van gedrag van doorwerking individuen of organisaties in lijn met de aanbevelingen van het advies.

Conceptuele Het advies heeft een verandering in de kennis, opvattingen of doorwerking causale redeneringen van individuen of organisaties tot gevolg.

Agenderende doorwerking Als gevolg van het advies wordt een nieuw onderwerp of beleidsthema onderwerp van het maatschappelijke of politieke debat; het advies heeft een agenderende functie.

Politiek- Het advies wordt gebruikt om de machtspositie van één of strategische enkele spelers te versterken om op deze wijze de politieke doorwerking doelen beter te kunnen bereiken.

Bron: figuur 2 uit Bekkers et al. (2004)

Binnen het lokale rekenkameronderzoek lijkt de meeste aandacht uit te gaan naar de instrumentele en de agenderende doorwerking. De instrumentele doorwerking kan worden onderzocht door na te gaan wat met de aanbevelingen van rekenkamers is gedaan. Heeft het bestuur de aanbevelingen overgenomen of niet? Agenderende doorwerking betekent dat een rekenkamer een bepaald onderwerp op de politieke agenda weet te plaatsen. Dat kan soms gaan om een onderwerp dat voorheen weinig tot geen aandacht kreeg, maar ook om een bestaand politiek onderwerp weer in de schijnwerpers te krijgen. ${ }^{2}$ De mate en duur van politieke aandacht voor een rekenkameronderzoek kan overigens sterk verschillen. Sommige onderzoeken blijven jaren lang hun invloed houden, andere onderzoeken komen na de formele aanbieding amper meer in het aandachtsveld van bestuur of ambtenarij.

Over wat precies de betekenis is van conceptuele en politiek-strategische doorwerking van rekenkameronderzoek is weinig bekend. Systematisch empirisch onderzoek hierover ontbreekt op dit moment nog.

\section{Definitie}

Doorwerking kan op individueel en op groepsniveau worden bestudeerd. Ons methodologische standpunt is dat voor onderzoek naar de doorwerking van rekenkameronderzoek een 'mixed method' de voorkeur heeft, dus nagaan wat een rekenkameronderzoek betekend heeft voor individuele functionarissen en voor het bestuur en beleid als collectief. Een theoretisch lastige discussie betreft de reikwijdte van het begrip doorwerking. De onderliggende vraag is dan wat nog wel en wat niet meer onder doorwerking valt. Wij bakenen doorwerking van rekenkameronderzoek begripsmatig af door het te plaatsen binnen besluitvorming over lokaal overheidsbeleid. We gebruiken de volgende definitie. 
Met doorwerking van rekenkameronderzoek bedoelen we het beïnvloeden van besluitvormingsprocessen door middel van het bieden van toepassingsgerichte kennis op basis van beleidsonderzoek, verricht door of in opdracht van een rekenkamer.

De definitie maakt duidelijk dat rekenkameronderzoek besluitvorming beïnvloedt en niet bepaalt. Dat is misschien een beetje een open deur, maar goed om te benadrukken. Rekenkamers zijn verantwoordelijk voor het doen van goed onderzoek, niet voor de uiteindelijke publieke besluitvorming en de effecten daarvan. In veel gevallen is rekenkameronderzoek overigens één van meerdere bouwstenen waarop tot formele besluitvorming wordt gekomen. Indien een aanbeveling van de rekenkamer in de beleidspraktijk overgenomen wordt, is dat dus toe te schrijven aan de bestuurlijke besluitnemers. Niet aan de rekenkamer zelf.

Besluitvorming bedoelen we hier in ruime zin. Het gaat niet alleen om het formele moment van besluitvorming in een raads- of statenvergadering. Het betreft ook de voorbereiding daarop. Bovendien wordt duidelijk dat we rekenkameronderzoek plaatsen binnen het bredere veld van het toegepaste beleidsonderzoek. Rekenkamers doen geen wetenschappelijk onderzoek, maar gebruiken wel wetenschappelijk onderbouwde methoden van onderzoek. Hoewel de wettelijke taakstelling doet vermoeden dat lokale rekenkamers alleen ex-post beleidsevaluatieonderzoek verrichten, blijkt de praktijk gevarieerder te zijn. Naast ex-post evaluaties zien we dat er ook andere vormen van onderzoek worden verricht. Twee voorbeelden zijn de verkenning naar demografische krimp (2011) door de Rekenkamer Oost-Nederland en de handreiking Keuzes voor Zeeland (2012) door de Rekenkamer Zeeland.

\section{Zes factoren voor doorwerking}

\section{BACKTO}

Uit de literatuur over doorwerking en eigen ervaringen heeft de auteur zes factoren gedestilleerd die van invloed zijn op de doorwerking of benutting van rekenkameronderzoek. We bespreken ze in de volgorde van de letters van het acroniem BACKTO. Het acroniem zelf heeft geen betekenis maar kan helpen om de factoren te onthouden. De eerste twee factoren (behoefte en attitude) hebben de doelgroep van het onderzoek als onderwerp. De derde factor (communicatie) betreft de relatie tussen rekenkamer en de doelgroep. In veel gevallen zijn er meerdere personen of organisaties die als doelgroep of als stakeholder te benoemen zijn. In het geval van lokaal rekenkameronderzoek wordt de gemeenteraad of provinciale staten veelal als primaire doelgroep gezien. 


\section{B A C K T O}

Behoefte van doelgroep

Attitude van doelgroep

Communicatie naar doelgroep

Kwaliteit van onderzoek

Timing van het onderzoek

Onderwerp van onderzoek

Het rekenkamerrapport wordt formeel ook aan hen aangeboden.

De secundaire doelgroep is het college van $\mathrm{B} \& \mathrm{~W}$ of gedeputeerde staten en de ambtelijke organisatie. Daarnaast kunnen er nog externe (buiten het lokaal bestuur) doelgroepen zijn, zoals onderzochte instellingen, andere overheden, burgers en anderen. De laatste drie factoren hebben het onderzoek zelf als onderwerp. We bespreken de zes factoren hieronder.

\section{Factor 1: Behoefte van doelgroep}

De kennisbehoefte van de doelgroep is van invloed op de doorwerking van (rekenkamer)onderzoek. In het algemeen geldt dat de doorwerking toeneemt als een onderzoek aansluit bij de behoefte aan bepaalde kennis. We wijzen erop dat die behoefte ook door het onderzoek zelf gecreëerd kan worden. Er bestaat veelal geen expliciete behoefte aan onderzoek naar onderwerpen die niet regelmatig op de politieke agenda staan of zelfs onbekend zijn bij de doelgroep. Onderzoek kan een einde maken aan zo'n blinde vlek.

Een goed voorbeeld is rekenkameronderzoek naar 'onderuitputting' of ook wel 'onderbesteding' genoemd. Onderbesteding is een financieel-technisch begrip dat erop wijst dat binnen een bepaald tijdvak niet het hele budget wordt uitgegeven. Het zijn hooguit de financieel specialisten uit een fractie die er kennis van hebben. Er zijn voorbeelden uit de praktijk dat rekenkameronderzoek heeft bijgedragen aan de bekendheid van de politiek met dit vraagstuk en dat de rekenkamer heeft kunnen overtuigen waarom het een probleem is.

Een goed en regelmatig contact met de raad of staten is van belang om de behoefte van de doelgroep te peilen. Dat betekent ook dat de rekenkamer het politieke debat op de voet volgt. Voor kleine rekenkamers is het moeilijker om in te spelen op de behoefte vanuit de politiek, omdat zij maar beperkte capaciteit en budget hebben om onderzoek te doen. Maar ook voor hen geldt dat regelmatig contact met de raad betekent dat de relaties worden versterkt, wat ook weer positief uitwerkt op de doorwerking (kennen en gekend worden). 


\section{Factor 2: Attitude van doelgroep}

Een factor die - tenminste binnen rekenkamerland - weinig aandacht krijgt, is de attitude van de ontvanger ten opzichte van wetenschappelijk en/of toegepast onderzoek. Er zijn nu eenmaal mensen die een negatieve basishouding aannemen tegenover de waarde en het praktische nut van onderzoek. Recente incidenten binnen de sociale psychologie doen het imago van dat vakgebied, en indirect het imago van de hele wetenschap en onderzoekers, geen goed. Zeker niet bijs mensen met toch al een negatieve houding die hun vermoeden bevestigd zien. Opvattingen over onderzoek, soms gebaseerd op een slechte ervaring, kunnen een sterke invloed hebben op de doorwerking. Die invloed kan twee kanten opwerken. Als uitersten zijn er mensen met een heilig geloof in de wetenschap, maar er zijn ook mensen met radicaal ongeloof. Wat voor rekenkameronderzoek meespeelt, is dat de rekenkamer als bestuurlijk instrument ook haar voor- en tegenstanders kent. Er zijn mensen, en soms hele politieke fracties, die bij voorbaat al weinig met lokale rekenkamers op hebben om politieke motieven. Het is dan lastig, hoe goed een onderzoek ook is, om hen te motiveren om het rapport ten minste te lezen, laat staan het daadwerkelijk te gebruiken. Het kan ook voorkomen dat er sprake is van verstoorde verhoudingen tussen (enkele leden van) de rekenkamer en een of enkele personen of bepaalde doelgroepen. Het is in zo'n geval van belang om de persoonlijke verhoudingen te verbeteren.

\section{Factor 3: Communicatie}

Naast behoefte en attitude is de communicatie naar de doelgroep belangrijk voor de doorwerking. De ingezette middelen en stijl van communicatie (zakelijke schrijfstijl en professionele lay-out) moeten de doelgroep uitnodigen om zich te verdiepen in het onderzoek. Als de boodschap van de rekenkamer niet overkomt, neemt de kans op een goede doorwerking uiteraard af.

Het is in de rapporten van belang een balans te vinden tussen volledigheid en relevantie. Veel onderzoekers hebben vanuit hun professionele achtergrond de neiging om een zo volledig mogelijke rapportage te maken van het uitgevoerde onderzoek. Een logisch gevolg daarvan is een dik rapport. Voor de doelgroep van raadsleden, statenleden en dagelijkse bestuurders nodigt een dik rapport niet uit tot lezen. Simpelweg omdat een rekenkamerrapport een van de documenten is op vaak een grote stapel van ander papierwerk. Het is aan te raden om daar rekening mee te houden door een heldere opzet van de rapportage. Er zijn goede ervaringen met het opdelen van een rapport in een bestuurlijk rapport en een onderzoeksrapport (ook wel nota van bevindingen genoemd). Het bestuurlijk rapport beschrijft de hoofdconclusies en aanbevelingen, en het onderzoeksrapport biedt de feitelijke onderbouwing. We zien een trend waarbij alleen nog het bestuurlijk rapport wordt geprint of gedrukt, en het onderzoeksrapport alleen nog maar digitaal wordt gepubliceerd. Dat drukt de kosten en ondersteunt een duurzaam gebruik van papier. Een nadeel is dat het onderliggende onderzoeksrapport vaak niet of amper meer gelezen wordt. Dat is een nadeel omdat het onderzoeksrapport veelal nuttige achtergrondinformatie biedt, die uit zicht bij de doelgroep blijft als alle aandacht uitgaat naar het bestuurlijk rapport.

Ten slotte is een goede presentatie van belang om de hoofdboodschap van de rekenkamer tussen de oren van de doelgroep te krijgen. Een goede presentatie wordt enthousiast gebracht en wordt ondersteund met interessant beeldmateriaal. Een bekende valkuil is dat de onderzoeker het hele onderzoeksproces en de uitkomsten wil samenvatten in twintig sheets in tien 
minuten. Dat komt niet over. Het is goed om de presentatie te beperken tot de hoofdboodschap en de vraag wat de raad of staten ermee kunnen doen.

\section{Factor 4: Kwaliteit}

De kennisbehoefte, attitude en ten dele ook de communicatie zijn factoren waarop een rekenkamer alleen indirect kan sturen. Voor de methodologische kwaliteit van het onderzoek geldt dat niet. Binnen rekenkamerland is veel aandacht voor kwaliteit en kwaliteitsontwikkeling. Onder meer via de koepelvereniging van rekenkamers (de Nederlandse Vereniging van Rekenkamers en Rekenkamercommissies), of handreikingen van adviesbureaus of de Algemene Rekenkamer. Kwaliteit van onderzoek is een typische noodzakelijke, maar niet voldoende voorwaarde voor doorwerking. Onderzoek van matige kwaliteit zal in het politieke debat over het onderzoek al snel sneuvelen en worden afgeserveerd. Lokale rekenkamers lijken zich daarvan goed bewust. Er is over het algemeen weinig kritiek op de kwaliteit van het rekenkameronderzoek in Nederland. Uitzonderingen daargelaten. Een veelgehoorde kritiek is zelfs dat rekenkameronderzoek wel erg netjes is en dat het wel wat spannender mag (zie bijv. BZK, 2011). De kritiek is intussen door enkele rekenkamers opgepakt en we zien zo hier en daar dat innovatieve onderzoeksmethoden worden gebruikt.

Een mooi voorbeeld daarvan is het inzetten van een 'schouw' als manier om zwerfvuil op straat in beeld te brengen. Het is verstandig om bij de inzet van een nieuwe onderzoeksmethode de doelgroep te polsen naar hun mening. Hoewel de doelgroep er niet over gaat, zijn er situaties geweest waarin een nieuwe methode de nodige weerstand opriep. Dan gaat het debat meer over de methode dan de resultaten van het onderzoek. Het is goed die discussie vooraf aan het onderzoek te hebben en niet erna.

\section{Factor 5: Timing}

Een goede timing van onderzoek is gemakkelijker gezegd dan gedaan. Dat heeft vooral te maken met de hoge dynamiek van de politieke arena in combinatie met de relatief lange doorlooptijd van onderzoek. Een onderzoek kan starten op het moment dat een bepaald onderwerp de politieke agenda domineert en eindigen op het moment dat de aandacht weg is. Daar is niet altijd goed op te plannen. Waar wel op te plannen is, is een geschikt moment van publicatie, bijvoorbeeld dat kennis uit een rekenkameronderzoek meegenomen kan worden in de ontwikkeling van een nieuw beleidsplan of als input voor een begrotingsdebat. Hier valt voor rekenkamers nog wel winst te halen. Er is al enige jaren kritiek op rekenkamers dat de publicatie van rekenkameronderzoek uit de lucht komt vallen. Het rapport wordt gepubliceerd als het klaar is en er wordt geen rekening mee gehouden of en hoe de publicatie past binnen het lopende bestuurlijke proces. Het zou goed zijn als rekenkamers al bij het opstellen van het onderzoeksplan nadenken over het tijdstip van publicatie. Ook overleg met de griffie kan helpen om het rapport op een goed moment te publiceren en te agenderen.

\section{Factor 6: Onderwerp}

De laatste factor die we bespreken, is zeker niet de minst belangrijke. Het onderwerp van het onderzoek bepaalt voor een belangrijk deel de aandacht in media en politiek voor een rekenkameronderzoek. En aandacht is van belang om als rekenkamer de boodschap te kunnen brengen. Onderzoeken naar een 
politiek gevoelig thema als declaraties of een mislukt bouwproject zullen zeker aandacht krijgen. Die aandacht kan overigens voor de doorwerking ook negatief uitwerken. Als een rapport veel stof doet opwaaien, kan een rapport zo politiek gevoelig worden dat een zakelijke behandeling ervan niet meer mogelijk is. Partijpolitiek en het uit de wind houden van een wethouder, of juist het schaden van het zittende college, kan dan het voornaamste doel worden. Het is als rekenkamer niet altijd mogelijk om vooraf in te schatten hoe een bepaald onderzoek zal vallen. Bij gevoelige thema's heeft het de voorkeur om vooraf met de raad of staten in overleg te gaan. Een breed gedragen verzoek om onderzoek vanuit de raad of staten kan dan helpen om het onderwerp minder politiek gevoelig te maken.

Voor de doorwerking op langere termijn is het verstandig om na te denken over de onderwerpselectie. De rekenkamer moet niet al te voorspelbaar worden door bijvoorbeeld veel onderzoeken te doen op hetzelfde of aangrenzende beleidsvelden. Ook altijd dezelfde insteek met gelijkluidende bevindingen leidt tot voorspelbaarheid en daarmee tot ingesleten reacties en een routineuze politieke behandeling. Een goed voorbeeld is de conclusie dat beleidsdoelen niet SMART geformuleerd zijn. Als rekenkamer kun je daar aandacht voor blijven vragen, maar een van de belangrijkste conclusies kan het na een paar keer niet meer zijn.

\section{Afsluitende opmerkingen}

\section{De volgende stap}

Het conceptualiseren en operationaliseren (wat is het, en hoe meten we het?) van vooral de conceptuele en politieke-strategische doorwerking van rekenkameronderzoek vragen nog het nodige denkwerk. Het is van groot belang dat dit gebeurt, omdat doorwerking op die manier vollediger in beeld kan worden gebracht dan alleen door naar het overnemen van de aanbevelingen te kijken. Het BACKTO-model biedt daarvoor geschikte aanknopingspunten. De volgende stap in de ontwikkeling van dit doorwerkingsmodel is na te gaan hoe het gebruikt kan worden in de evaluatie van de rekenkamerpraktijk of eventueel de analyse van de doorwerking van andere beleidsonderzoeken. Het gaat nu dus om het operationaliseren van het BACKTO-model en vervolgens om de stap te maken het model daadwerkelijk in de praktijk te gebruiken. We willen erop wijzen dat het gebruik van het BACKTO-model ook consequenties heeft voor de opzet van de evaluatie van rekenkamers. Naast de gebruikelijke methoden van documentanalyse, een enquête aangevuld met interviews, willen we hier een lans breken voor het houden van een rondetafelgesprek tussen rekenkamer en vertegenwoordigers van de raad of staten. Die methode is nodig om, onder leiding van een onafhankelijke gespreksleider, dieper in te gaan op vooral de conceptuele en strategische doorwerking. Die vormen van doorwerking komen bij interviews en zeker bij enquêtes amper of te beperkt aan de orde.

\section{Ten slotte}

In dit artikel is het BACKTO-model gepresenteerd als een nieuw en meer volledig model om de doorwerking van rekenkameronderzoek te onderzoeken. Een goede kijk op doorwerking is van belang om in beeld te krijgen wat de 'meerwaarde' van de gemeentelijke of provinciale rekenkamer is geweest. Het is belangrijk voor de rekenkamer om te weten waar haar meerwaarde zit om daarmee de raad of staten zo goed mogelijk te kunnen ondersteunen in hun controlerende en kaderstellende rol. 


\section{Literatuur}

Bekkers, V., Fenger, M., Homburg, V., \& Putters, K. (2004). Doorwerking van strategische beleidsadvisering. Erasmus Universiteit Rotterdam / Universiteit van Tilburg.

Ministerie van Binnenlandse Zaken (2011). Leren van evalueren. Onderzoek naar het gebruik van evaluatieonderzoek bij het ministerie van Buitenlandse Zaken.

\section{Noten}

1 Bekkers et al. geven in hun publicatie een beknopt overzicht van de theoretische achtergronden van het concept doorwerking en refereren naar het werk van bestuurskundigen als Hoppe, Sabatier \& Jenkins-Smith en Weiss.

2 Er wordt in de praktijk ook wel gesproken van voorwerking of de preventieve werking van een rekenkameronderzoek. Dat betekent dat het lopende beleid op onderdelen al aangepast wordt, omdat ambtenaren en/of bestuurders weten dat een rekenkameronderzoek opgestart zal worden. 